\title{
UNIDOBEM - UM PROJETO DE EXTENSÃO MULTIDISCIPLINAR NA COMUNIDADE GRÃO DE MOSTARDA
}

\author{
UNIDOBEM - A PROJECT OF MULTIDISCIPLINARY EXTENSION IN THE COMMUNITY \\ GRÃO DE MOSTARDA
}

\begin{abstract}
Autores
Stania Nagila Vasconcelos Carneiro. Pós-doutora em Literatias e Ensino da Língua na Universidade do Minho

Docente do Programa de Pós-Graduação da Unicatólica do Centro Universitário Católica de Quixadá. Ceará. Brasil.

Docente participante do Grupo de Extensão e Pesquisa UNIDOBEM

Email: stanagila@hotmail.com
\end{abstract}

Lucimara Araújo de Mesquita. Discente do curso de Odontologia. Participante do Grupo de pesquisa e extensão UNIDOBEM. Centro Universitário Católica de Quixadá. Ceará. Brasil

Email: lucimaraaraujo@unicatolicaquixada.edu.br

Elane Maria de Castro Coutinho. Mestre em Economia. Docente do curso de Farmácia da Unicatólica. Coordenadora do Grupo UNIDOBEM. Centro Universitário Católica de Quixadá. Ceará. Brasil

Email: elanecoutinho@unicatolicaquixada.edu.br

Sofia Vasconcelos Carneiro. Mestre em Odontopediatria. Docente do curso de Odontologia da Unicatólica. Doutoranda em Odontopediatria.

Participante do Grupo UNIDOBEM. Centro Universitário Católica de Quixadá. Ceará. Brasil

Email: sofiavasconcelos@unicatolicaquixada.edu.br

Recebido em: 02/11/2018 Aprovado em: 07/01/2019

DOI: 10.12957/interag.2018.31091

\section{Relato}

O presente trabalho relata a experiência de um projeto de extensão universitária envolvendo cursos, docentes e discentes da área de saúde, exatas e humanas do Centro Universitário Católica de Quixadá por meio de um convênio firmado com a organização não governamental Grão de Mostarda. Temos como finalidade apresentar as principais ações realizadas por acadêmicos extensionistas, abordando o histórico do projeto de extensão e a im-

\begin{abstract}
The present work reports the experience of a university extension project involving courses, teachers and students of the health area, exact and human of the Catholic University Center of Quixadá through an agreement signed with the non - governmental organization Grão de Mostarda. We aim to present the main actions carried out by extensionist academics, addressing the history of the extension project and the importance of
\end{abstract}


portância da interação ensino-serviço- comunidade para formação acadêmica através de projetos multidisciplinares. $\mathrm{O}$ projeto segue uma linha descritiva e exploratória, onde se busca, através de um relato, analisar as atividades multidisciplinares desenvolvidas no Projeto UniDoBem pelos discentes da IES, visando conhecer as características, as relações, as causas e a natureza de fatos não explorados na comunidade carente. Observou-se nos acadêmicos extensionistas o desenvolvimento de uma atitude humanística em relação aos problemas de saúde e sociais na população possibilitando aos discentes os conhecimentos essenciais sobre a realidade da sociedade em que vivem, na qual e para a qual irão trabalhar.

Palavras- chave: Integração. Ensino. Comunidade. Extensão

Área Temática: Educação e Saúde Linha Temática: Infância e adolescência; Saúde humana; Grupos sociais vulneráveis teaching-service-community interaction for academic training through multidisciplinary projects. The project follows a descriptive and exploratory line, which seeks, through an account, to analyze the multidisciplinary activities developed in Projeto UnidoBem by the students of the IES, aiming to know the characteristics, the relations, the causes and nature of facts not explored in the community in need. It was observed in extension academics the development of a humanistic attitude towards health and social problems in the population, allowing the students the essential knowledge about the reality of the society in which they live, in which and for which they will work.

Keywords: Integration. Teaching. Community. Extension

\section{Introdução}

As atividades relacionadas à responsabilidade social têm ganhado cada vez mais destaque na sociedade. Vários tipos de organizações se tornaram adeptos desta causa. Neste contexto, para Reis e Bandos (2012), as contribuições das Instituições de Ensino Superior (IES) possuem um patamar mais elevado, pois promovem grande impacto na geração de conhecimento e formação de profissionais.

A partir da realização de ações de extensão, a IES se aproxima da sociedade na qual está inserida, visando cumprir a disseminação de conhecimentos e a troca de saberes com a comunidade. Nesse processo, a instituição de ensino, segundo Nunes ${ }^{2}$, oferece aos discentes a oportunidade de adquirir experiências de aprendizagem e, em troca, a comunidade acadêmica é beneficiada com a oportunidade de compartilhar conhecimento, adquirido por meio do ensino e da pesquisa desenvolvidos na instituição, com o público externo².

Este trabalho tem, pois, como objeto de análise, em uma primeira aproximação, a compreensão da importância do projeto de extensão interdisciplinar e multidisciplinar na con- 
formação do perfil profissional proposto pelo Centro Universitário Católica de Quixadá.

Busca-se, por meio deste artigo, relatar algumas características importantes do projeto de extensão UNIDOBEM, do Centro Universitário Católica de Quixadá, que envolve alunos dos cursos de Odontologia, Farmácia, Teologia, Psicologia, Direito, Arquitetura e Enfermagem, firmando, assim, a contribuição, ou mesmo, a participação desta Universidade junto à comunidade local.

\section{Desenvolvimento}

De acordo com as Diretrizes para a Extensão Universitária definidas pelo Programa Nacional de Extensão, ${ }^{3}$ ações dessa natureza sempre devem apresentar quatro eixos fundamentais: impacto e transformação, interação dialógica, interdisciplinaridade, e indissociabilidade entre Ensino-Pesquisa-Extensão. É neste cenário de contextualização do que vem a ser a Extensão universitária como progresso educativo, cultural e científico que surge a possibilidade de troca de saberes em que ambas as partes são favorecidas.

Conforme Souza et al. ${ }^{4}$, a metodologia científica promove o contato entre o conhecimento e a análise crítica, proporcionando a ampliação do saber. Assim, conclui o autor, que o processo de ensinar e divulgar o procedimento científico são objetivos da universidade.

A metodologia empregada no projeto UniDoBem segue uma linha descritiva e exploratória, onde se busca realizar atividades multidisciplinares entre os cursos da Unicatólica, visando conhecer as características, as relações, as causas e a natureza de fatos não explorados na comunidade carente Grão de Mostarda. Dessa forma, a análise crítica do que é necessário é possível, propiciando a tomada de decisão, no que diz respeito à elaboração de ações, trabalhos científicos do tipo relato de experiências e outros, além da discussão de opinião. As atividades do núcleo têm por base a interação na comunidade, prestando serviços como: atendimento odontológico, educação em saúde, verificação de glicemia, pressão arterial e peso, orientação de dieta e exercícios posturais. As atividades são desenvolvidas dois dias a cada mês (de acordo com a disponibilidade dos cursos).

O projeto de extensão UNIDOBEM tem a finalidade de proporcionar uma formação acadêmica integral, contextualizada na realidade social do aluno, além de promover a integração Universidade-comunidade. O projeto UNIDOBEM atua na comunidade desde 2016, sendo composto por professores e acadêmicos dos cursos de Farmácia, Arquitetura, Odontologia, Direito, Enfermagem, Educação Física, Fisioterapia, Administração e Teologia da Unicatólica. São desenvolvidas ações de extensão, quinzenalmente, na comunidade Grão de Mostarda, localizada no bairro Campo Novo, em Quixadá-Ceará. O projeto vem buscando mudanças na realidade dessas crianças e, aos poucos, está conseguindo o resultado esperado, como a diminuição das cáries dentárias nas crianças, inserção das famílias nas ações e ampliação das instalações físicas da associação.

\section{Associação Grão de Mostarda}

A Associação Grão de Mostarda foi fundada em 2004 por um grupo de jovens do município de Quixadá e por uma italiana, que, naquela época, fazia parte de outra ONG. Ao constatar que a ONG da qual fazia parte não correspondia às suas expectativas, resolveu reunir-se com o grupo de jovens e realizar o sonho de criar uma nova ONG, cuja finalidade seria tirar da rua as crianças que moravam no Bairro Mutirão, uma área de risco no município. Assim, retornou à Itália com o propósito de conseguir recursos para comprar uma casa no Bairro e plantar a semente do Grão de Mostarda. O projeto foi concretizado 
e, assim, nascia a Associação Grão de Mostarda, que acolhe crianças que moravam na região ao redor.

Hoje a Associação ampara cerca de 200 crianças, fornecendo alimentação, educação escolar, aulas de dança, informática e teatro. Atualmente, a ONG é mantida com a ajuda de pessoas da comunidade e doações das fundadoras.

\section{Atividades de Extensão UniDoBem}

O projeto de extensão UniDoBem visa contribuir na construção de um futuro melhor para as comunidades circunvizinhas, especialmente as carentes, proporcionando serviços e orientações técnicas com a participação dos cursos de Farmácia, Odontologia, Psicologia, Teologia, Direito, Enfermagem, Fisioterapia e Arquitetura proporcionando aos acadêmicos a convivência com a realidade social e criando um espaço de prática profissional. A importância desta proposta está em conhecer o desenvolvimento socioeconômico e ambiental na comunidade, com vistas a fortalecer as organizações populares, conduzindo à autonomia para a tomada e implementação de decisões, com base numa cooperação organizada de esforços. Além disso, objetiva prestar serviços que beneficiam as comunidades, integrando vários cursos da Unicatólica, ou seja, a prática inter e multidisciplinar.

Trata-se, portanto, de um programa multidisciplinar que busca promover a integração entre serviço-ensino-comunidade, proporcionando ao aluno de graduação o conhecimento da realidade social, econômica, cultural, demográfica, urbana e rural da localidade na qual está sediado, bem como a aproximação de diferentes cursos de graduação visando o estudo da comunidade de forma integral.

A metodologia empregada no UniDoBem segue uma linha descritiva e exploratória, nas quais se busca realizar atividades multidisciplinares entre os cursos da Unicatólica. Estas atividades visam conhecer as características, as relações, as causas e a natureza de fatos não explorados na comunidade carente Grão de Mostarda. Assim, as atividades do núcleo têm por base a interação da IES junto à comunidade.

\section{Cursos de Farmácia e Odontologia}

Os acadêmicos dos cursos de Farmácia e Odontologia desenvolveram atividades com, aproximadamente, 150 crianças. O momento foi marcado com um almoço e, posteriormente, foram realizadas palestras sobre a doença cárie, com gincanas e escovação supervisionada.

“Esse momento foi muito gratificante para que nós possamos conhecer realmente a realidade em que vivemos. Eu e os colegas ficamos muito sensibilizados com a situação e pretendemos realizar atividades com a turma inteira da faculdade" relata Lucimara, acadêmica do Curso de Odontologia.

Para o aluno de Farmácia, Assis Jr.:

“É a primeira vez que participo do projeto, e é realmente muito enriquecedor para todos nós que fazemos parte do projeto, ver o sorriso estampado no rosto daquelas crianças, que nos leva a querer fazer cada vez mais por elas. Então que venham mais momentos como esse, não vejo a hora de poder revê-los novamente e levar alegria e um pouco do meu conhecimento para melhorar a vida de cada um". 


\section{Curso de Psicologia}

O curso de Psicologia desenvolveu atividades lúdicas com três turmas de crianças, de acordo com as faixas de idade de 2 a 5 anos, 6 a 9 anos e acima de 9 anos. A contação de história com temáticas acerca de questões inerentes ao desenvolvimento infantil foi o foco. Temas como imaginação, medo, timidez e conhecimento sobre o próprio corpo foram trabalhados com as crianças, que expressaram suas dúvidas, inquietações e vivências e foram ajudados a compreender tais questões, por meio do diálogo propiciado pelas interações lúdicas que incluíram também o desenho livre.
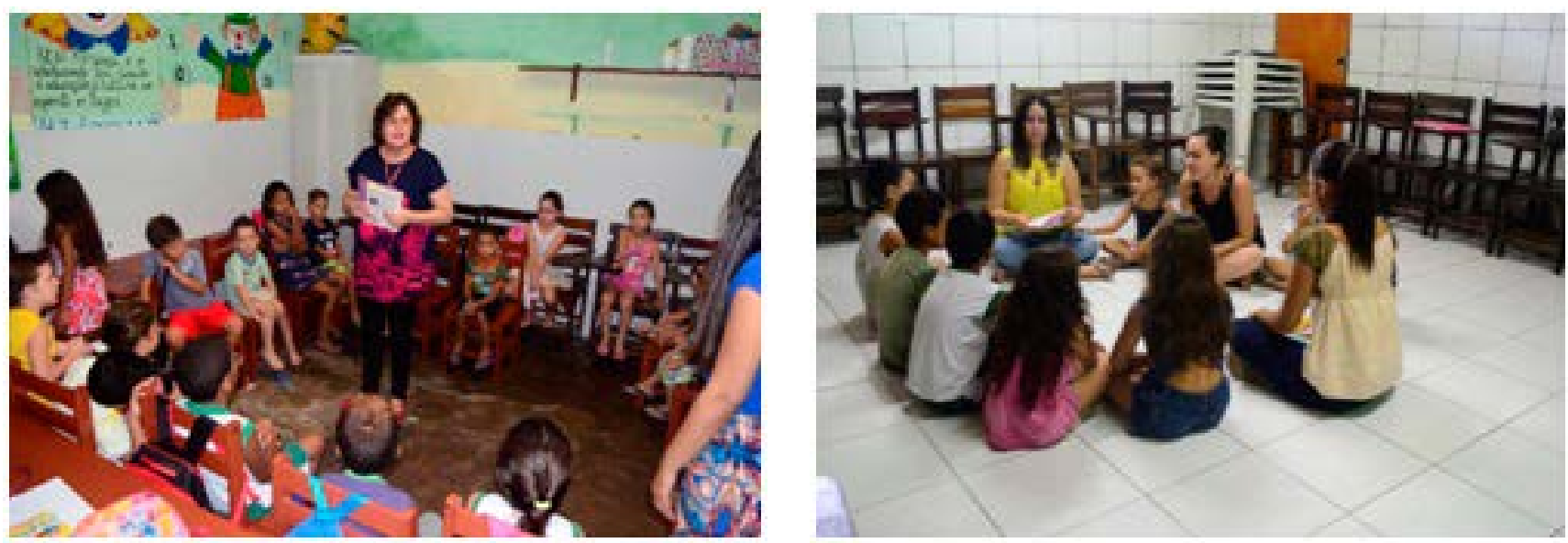

FIGURAS 1 e 2 - Ação do Curso de Psicologia com as crianças da Comunidade

\section{Cursos de Teologia e Direito}

Na semana da Páscoa, cerca de 60 crianças que frequentam a Associação passaram parte do dia conversando sobre o verdadeiro sentido da Páscoa, época tão significativa para os cristãos. Depois de assistirem a pequenos filmes sobre o assunto, as crianças falaram sobre o que esta época significa para elas, e, em seguida, foi explicado, pelos discentes de Teologia, que Jesus é a verdadeira Páscoa: Ele é o Cordeiro Pascal que foi morto para nos dar a vida. Para encerrar, depois de uma oração conduzida pelas crianças, chocolates foram trocados entre todos, acompanhados por fortes abraços carregados de euforia, carinho e alegria.

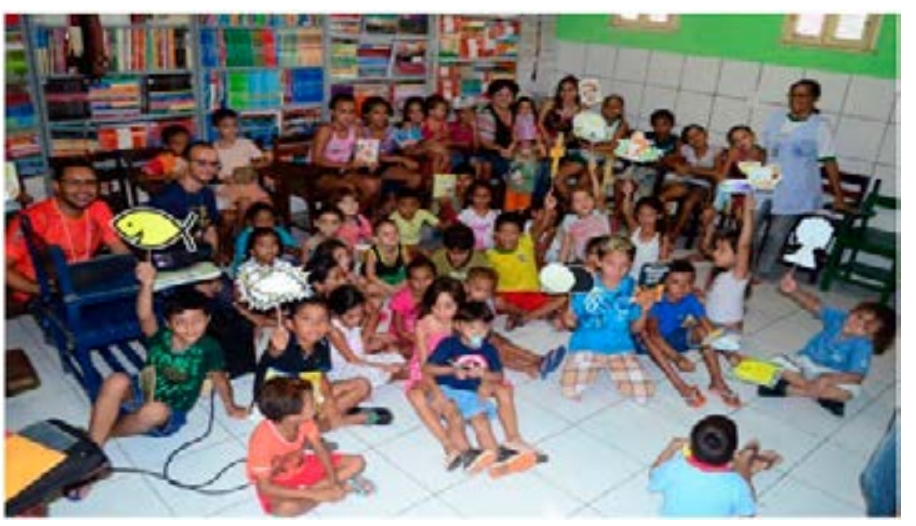

FIGURA 3 - Alunos e professora de Teologia em atividade sobre a Páscoa na Comunidade 


\section{Cursos de Odontologia, Farmácia e Teologia}
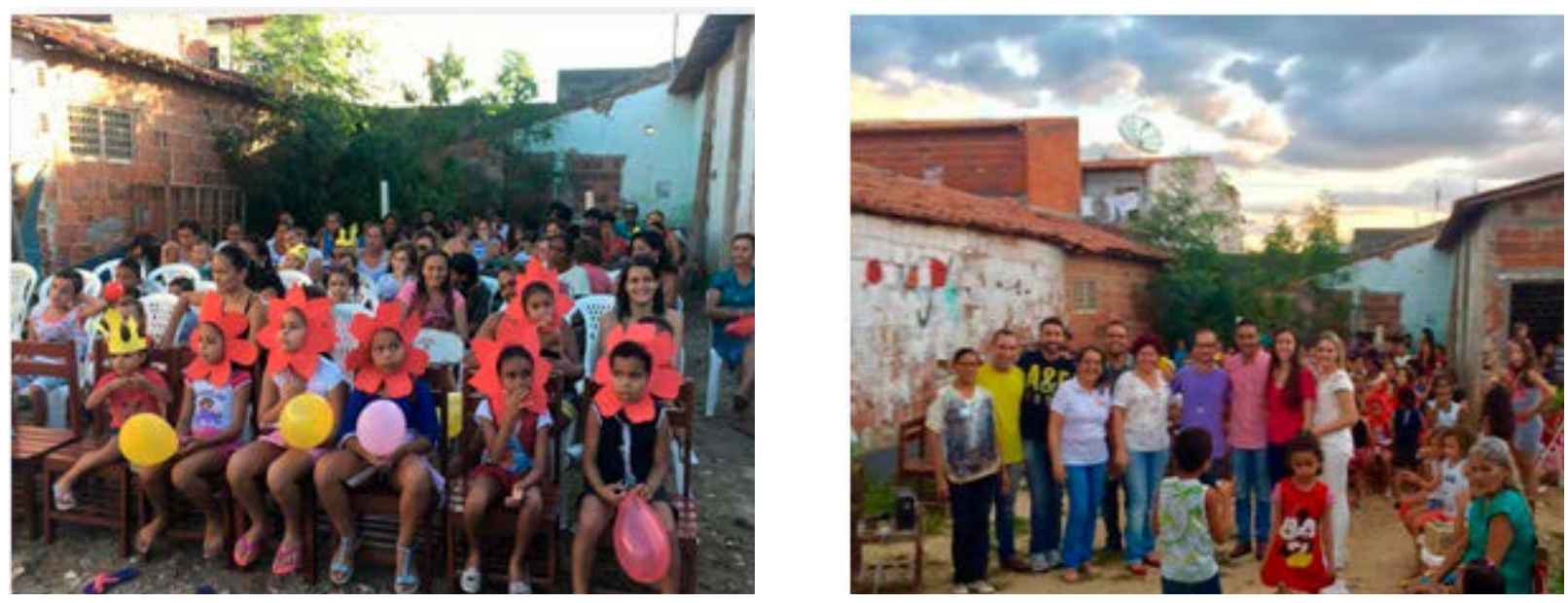

FIGURAS 4 e 5 - Homenagem às Mães: crianças homenageando as mães e os docentes e discentes da Unicatólica envolvidos na ação.

Com o tema "Mãe, um presente divino! ", os acadêmicos do curso de Teologia, Farmácia e Odontologia realizam uma homenagem às mães da Associação Grão de Mostarda. Houve uma interação entre acadêmicos da Unicatólica e crianças, em que foram preparadas danças, música, mensagens, entrega de chocolates e oração. Foi servido, ainda, um lanche para, aproximadamente, 60 mães e demais presentes.

\section{Cursos de Arquitetura e Enfermagem}

Acadêmicos do curso de Arquitetura realizaram um levantamento arquitetônico da Associação Grão de Mostarda, a fim de proporem melhorias e ampliação do espaço para as atividades desenvolvidas pela organização. Enquanto isso, o Curso de Enfermagem, através da disciplina de Saúde Coletiva, realizou uma ação educativa, na qual se abordou aspectos relativos à higiene infantil. Houve um teatro de fantoches e atividades de pintura educativa.
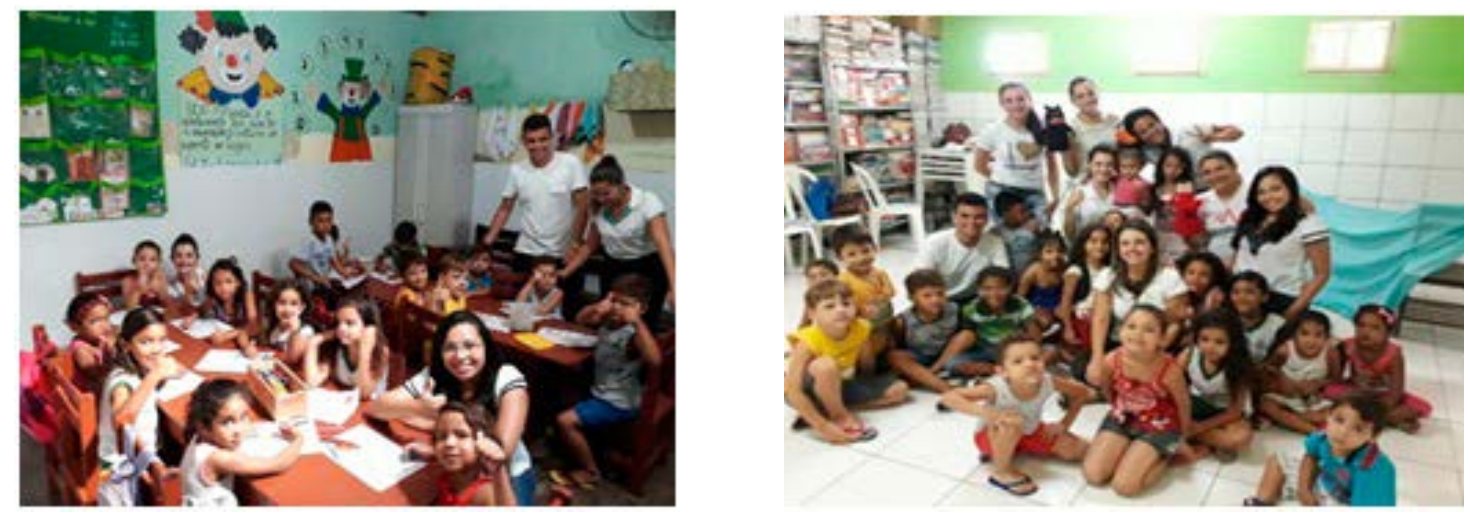

Figuras 6 e 7 - Comunidade recebe os discentes de Arquitetura e Enfermagem. FONTE: Unidobem,2017. 
A realização dessas atividades de Extensão segue um caminhar coletivo e cooperativo, com interlocução entre profissionais, alunos e parceiros externos à Universidade, em busca de uma ação cidadã para superar as situações de desigualdade e de exclusão existentes no Brasil. Nesse sentido, as ações de Extensão sob forma do projeto UNIDOBEM estão voltadas para o desenvolvimento do país, para a melhoria da qualidade de vida da população e a busca da cidadania consciente, bem como têm a preocupação de fazer dos movimentos extensionistas instâncias a partir das quais se possa sempre repensar os cursos de graduação e promover a melhoria contínua dos seus projetos político-pedagógicos.

\section{Considerações Finais}

A implantação da extensão universitária é um caminho para capacitar o futuro profissional nas questões sociais. Para Vieira et al (2017), as atividades extensionistas desenvolvem no acadêmico uma atitude humanística em relação aos problemas de saúde e sociais na população, pois que destaca o indivíduo, procurando dar a oportunidade aos alunos de possuírem os conhecimentos essenciais sobre a realidade da sociedade em que vivem, na qual e para a qual irão trabalhar.

As atividades de Extensão na Unicatólica assumem, assim, este caráter interdisciplinar e essa nova postura. Segundo a literatura na área e, considerando-se que ela é indissociável do Ensino e da Pesquisa, é destinada a articular o saber científico e o saber popular, perdendo o caráter assistencialista e assumindo-se como trabalho social, instrumento de democratização, autonomia universitária e de ação transformadora.

\section{REFERÊNCIAS}

1. A A. L. REIS; M. F. C. BANDOS. A responsabilidade social de instituições de ensino superior: uma reflexão sistêmica tendo em vista o desenvolvimento. Revista Gestão \& Conhecimento. ISSN 1808-6594. Edição especial - Nov/2012.

2. NUNES, A. L. F. A extensão universitária no ensino superior e a sociedade. Mal-Estar e Sociedade - Ano IV - n. 7 - Barbacena - julho/dezembro 2011.

3. FORPROEX - FÓRUM DE PRÓ-REITORES DE EXTENSÃO DAS UNIVERSIDADES PÚBLICAS BRASILEIRAS. Plano Nacional de Extensão Universitária. Ilhéus: Editus, 2001. (Extensão Universitária, v.1).

4. SOUZA, G. S.; SANTOS, A. R.; DIAS, V. B. Metodologia da pesquisa científica: a construção do conhecimento e do pensamento científico no processo de aprendizagem. Porto Alegre: Editora Animal, 2013.

5. VIEIRA, Alessandra Bandeira et al. FORMAÇÃO DOCENTE PARA UMA EDUCAÇÃO DE QUALIDADE. Revista Expressão Católica, [S.I.], v. 5, n. 1, aug. 2017. ISSN 23578483. Disponível em: <http://publicacoesacademicas.unicatolicaquixada.edu.br/index. php/rec/article/view/1479>. Acesso em: 09 Fev. 2018. doi:http://dx.doi.org/10.25190/ rec.v5i1.1479 